\title{
Everyone Can Be Composer Today - Full Stop or Question Mark?
}

Michal Rataj / michal.rataj@hamu.cz

Department of Composition, Music and Dance Faculty, Academy of Performing Arts, Prague, CZ

\begin{abstract}
The incredible tempo of technological development has been incomparable with the rapidity of paradigm shifts in art, particularly over the past 25 years of the "digital age". Approaching technology using its surface control level as an easy tool for art creation (due to lack of time while exploring it, or lack of knowledge, or just due to superficiality) is not often challenging enough to compete with core traditions of art craft across creative disciplines. Due to the rising complexity of user interfaces technologies require either more knowledge, experience and specialization, or provide their users with simplifying solutions.

Technologies also do not represent only pool of tools to be used. From media point of view, they gradually incorporate history of knowledge and its continuity. Using piece of technology to make music does not necessarily mean we understand how music is created on its structural level. We become composers thanks to knowledge embodied in the technology itself. Thanks to preset-based-technologies everyone can become composer today reaching quite complex results.

In my presentation I am addressing issues of craft and virtuosity in contemporary music composition and performance and I am looking for ways how deep music knowledge can be taught and developed through use of technologies.
\end{abstract}

\section{Keywords}

new musical instruments, contemporary composer's status, sound performance, radioart, art education 
Before I get to several specific points below, I'd like to demonstrate briefly a background, which has formed my experience and attitudes to the symbiosis of music and technology. The background consists of two worlds:

- being a composer myself along with an ongoing teaching position at the department of composition, Academy of performing arts, Prague,

- a 15 year position of a radio art producer in the Czech Radio - the public service media organization.

I am particularly mentioning these two worlds, because I feel they resemble a good portion of what we have been able to follow in the global music scene across genres, disciplines and creative backgrounds. The first world is represented by the academic background of "the official educational system", where we learn or teach about how things have been organized in the world (of music). The other - at least for me - represents an ongoing search for challenging forms of sound creativity stimulated by the technological means of radio or internet as media, or even more: by a studio as music instrument either a large official one, or a small subversive one.

\section{Radioart And Beyond}

My engagement with radio programming has been tied-up with the program called Radioatelier. It made its debut on the $25^{\text {th }}$ of January 2003, and began bringing new compositions from the world of the acoustic arts to Czech Radio. That day marked the opening of a new exploration of the Czech sound art scene. The feeling that accompanied this formulating of the initial principles can be described as a tabula rasa. The program lay somewhere between the surviving pioneering myths about electro-acoustic music from the period before the Velvet revolution of 1989, and the flood of new information that began to fill in the gaps of knowledge and experience after that year. That ambiguous orientation gave rise to a number of questions that were of crucial importance to me at the beginning of such an orientation:

what do all these terms such as sound art, radio art, ars acustica, radiophony, sonic art, or the acoustic arts mean in the context of the contemporary Czech scene?

How the Czech scene will be positioned within the global art context?

How can such a program be defended within a broadcasting institution?

Who will be the artists who should start making new sound works?

How can they be approached? ${ }^{1}$

1 For more details on the radioart initiative in the Czech Radio see RATAJ, Michal: Electroacoustic Music and Selected Concepts of Radio Art. PFAU Verlag 2010. [cit. 2016-11-18]. URL: <http://www.pfau-verlag.de/ pdf_art/27405.pdf>. Czech edition: RATAJ, Michal: Elektroakustická hudba a vybrané koncepty radioartu. AMU \& KANT, Praha 2007. 
With broken continuity in all areas of society after 1989 we started a new race in exploring what is the medium of sound in 2003 and how is it functioning among artists from different backgrounds. ${ }^{2}$ As late as in my 30s I was about to realize what in other countries had been evident decades ago: sound as a medium acts as a common denominator to composers as well as poets, film makers, visual artists and DJs as well as theatre performers.

At the end of 2016 I am able to enumerate 143 new sound works in the Radioatelier program, which were not only composed by Czech artists - during the past 15 years the program has become an integral part of global audio culture featuring artists form around the world including Australia, Brazil, Canada and of course Europe.

As for today, the 29 minute program introduces new work every last Friday of the month and the authors are inter-media artists, poets and voice performers, experimental musicians and radio feature makers, soundscape artists and theatre makers, improvisers and conceptual artists. And of course - composers, those old fashioned guys who normally write scores and distribute parts to their performers.

For all those artists, the sound studio (to quote Brian Eno) became a musical instrument in order to give new shapes to sound in time. And they have all been able to deal with sound and music technologies, often without professional music training, due to accessible technologies.

My position in academia makes me think more deeply about what I have been able to follow as a music producer since 2003 and how this matches (or disonates) with what we usually deliver to students as the core tradition of music composition. There are at least two areas, which I'd like to address below:

- how contemporary, often technologically based music making emerges with the traditional knowledge of global music history,

- how academia reflects the wide internet knowledge base on music and vice versa.

Since around 2005 tools for music creation have been everywhere as part of the generic digital world we use and touch as customers. We all carry elementary studio tools in our laptops and iPADs. Technology, with its strong engine in business and innovation, tends to hide fundamental features and potentials under the surface of immediate consumption/gratification while constantly touting new business \& market solutions. Developers tend to say "use the tool this way and do not think much about the rest". While providing a series of ready-made solutions they tend to suppress the potential of more complex uses, which await discovery.

On the one hand creativity serves innovation as a pool of ideas and impulses to develop new technology in order "to be used". On the other hand - you'll probably agree - art does not exist primarily in order to be used. It exists in order to be. That's a fundamental difference and during my years of pedagogical engagement I can observe how

2 RATAJ, Michal: Discontinuity, paradigm change and new crafts of sound composition, in: Electronic Music Today. Where are we going and what are we doing. Martin Flašar - Daniel Matej - Michal Rataj (eds.). Janáčkova akademi múzických umění v Brně, 2014, p. 14-27. 
deeply this dichotomy has been present in the ways young artists use different technological tools in their art explorations and creations. Oftentimes they tend to deal with easy solutions, because they have been available.

Facing current technologies, as artists, we usually understand "the surface", the user interface of technological tools, not interacting so frequently with the "technological content" of tools themselves. But even understanding user interfaces properly requires increasing effort, since their complexity has recently become enormous. As artists we approach technology in order to create a piece of art. Thus the technology itself becomes part of the work's conceptual frame, which usually requires more than writing a perfectly defined software code or creating a piece of advanced engineering. It requires equilibrium among multiple approaches within a complex framework of creative process, including the technological one, and it gives the technology conceptual meaning.

The incredible tempo of technological development has been incomparable with the rapidity of paradigm shifts in art, particularly over the past 25 years of the "digital age". Approaching technology using its surface control level as an easy tool for art creation (due to lack of time while exploring it, or lack of knowledge, or just due to superficiality) is not often challenging enough to compete with core traditions of art and craft across creative disciplines. Due to the rising complexity of user interfaces technologies require either more knowledge, experience and specialization, or provide their users with simplifying solutions. It seems like the second case becomes more usual when observing the contemporary digital art domain and when trying to dive below the typical user interfaces with my students. The business engine of technological development and our increasing powers of consumption emphasize the former too. Using an aphorism everyone can become a composer today upon touching the display of a smartphone. ${ }^{3}$

\section{Making New Instruments}

\section{[GESTRUMENT performance] ${ }^{4}$}

It's not a Jesper Nordin's composition we are listening to. It's you performing a new piece with your finger based on settings inside your tablet. But it IS Jesper Nordin's craft of composition YOU take now into your hands (thanks to the interface) and make music, which you'd probably mark with your copyright.

And I could quote a series of tools available today in our computers, which consist (on a code level) of large portions of knowledge, particularly in the realms of pitch and rhythm structuring, sound analysis, synthesis and re-synthesis. Behind them we can fol-

3 This issue could be well followed in the introductory text to the Proceedings of the ICMC 2016. TIMMERMANS, Hans, ed.: Is the sky the limit? Proceedings of the 42st International Computer Music Conference, 12-16 September 2016.

4 The author of the article conducted short sound performance using an iPAD with the Gestrument software instrument by the Swedish composer Jesper Nordin. For more details on the instrument see [cit. 2016-11-18], URL: 〈http://www.gestrument.com>. 
low an incredible amount of research and compositional effort. In order to use them, we don't need to undergo particular research again - that has been done by our fellow composers and sound engineers over the past couple of decades. And it's available to us now. The added value we give as composers is using them intentionally as real music instruments, which we master following their sonic, expressive and virtual-acoustic behaviour.

\section{(Non-)Exclusivity}

It seems to me there is no room for any kind of exclusivity of electro-acoustic music anymore. As composers and performers we no longer pioneer early electronic works. We shouldn't be protected under the auspices of numerous electro-acoustic music collectives, festivals, competitions or dedicated university programs. In our daily lives we also won't divide people according to whether they use an internet or special app to cook, or use an old fashioned cookbook.

Technology-based music creation should no longer be "the other". We should be able to understand orchestral scoring from a position of studio mixing as well as understand sound synthesis based on how traditional instruments work in an ensemble. And we should understand composing sound in time from a perspective computers teach us, while focusing on both micro- and macroscopic levels of how sound exists around us. ${ }^{5}$

It is the knowledge we obtain through the perspective of technology in music, which forms the way we understand the whole music tradition around the globe. As composers, we need to understand digital tools in music as if they were music instruments - based on their acoustical, technological, expressive and compositional potential, both from performative (interpretation) or compositional (structural organizing) point of view.

\section{Solutions}

In order to establish a creative framework between artist and technology, it seems that:

- technological development must be "privately stopped" for a period so that a tool of interest can be selected and accepted,

- new strategies, fundamental conceptual frameworks and relevant methodologies of human-technology interaction need to be developed so that a piece of technology becomes instrumentalized, or "hacked" according to suggested ways of use,

- "practicing such a new instrument" must happen despite the fact it results in a strange dichotomy: A) when I master a new piece of technology in my artistic practice, the technology becomes obsolete, B) the fact that technology becomes obsolete is counterbalanced by the added value of a developed human-technology interaction, which is only possible over a period of time.

5 Great introduction to the notion of „sound as music“ could be text by LANDY, Leigh: La musique des sons / The Music of Sounds. MINT - Série Musique et nouvelles technologies nr. 3-2007, 
Following such a dichotomy I would like to demonstrate several practical points, which I have been experiencing as an artist myself; radio producer or music instructor facing technologies as part of musical creation.

\section{(1)}

Several years ago I went to give a lecture at our film faculty about the MAX programming environment for the sound studies program. A few students came along with their instructor. I asked why there were not more students coming? He replied: "That's nothing for them, they don't have time for such complicated things..."

Diving deep under the surface of various privately selected tools and discovering their real artistic potential - this brings us over to an improvisational and naive approach to controlling them and creates intellectual and performative added value. Big artworks often don't appear to be very complicated, but they usually reveal a large portion of craft under their surface, or behind the conceptual front line. I am talking about this "craft", which is based on real knowledge - practical (performative) or intellectual (compositional, contextual).

We should be ready for not being up to date with technology on a daily base forever in order to avoid working on its surface.

\section{( 2 )}

Oftentimes good artists (composers or performers) consider digital technology as rather negative, or at least not so challenging with regard to the physical act of art making. I feel this has resulted in a huge revival of all kinds of non-digital-based musical instruments (analogue machines, tape recorders, home made sound objects) and hacking acoustic ones in order to reach new timbral / performance / compositional results, which otherwise would not be reachable, when playing such instruments in traditional performance contexts. A lack of physical expression in music calls back for "hardware" solutions. Performers realize, that the real physical act needs to be responsible for audible expression in delivering a "message of sound". Also the enormous rise of a global improvisational scene can be seen as a result of this technology-based issue.

A strong dichotomy of digital (software) and analog (non-digital, physical) has become an integral part of the contemporary music scene. My interpretation is that we re-discover relationships among things and ideas after they have been constituted parallel by postmodernists. We re-discover analogue through the perspective of digital. Or even better - we re-discover traditional musicality through the perspective of the digital music experience. 


\section{( 3 )}

We have followed an incredible amount of new technological instruments, which reflect on shifting creative and performance paradigms. Facing a variety of new interactions and sensing - as composers and performers we often accept a position of "you can do this...", instead of mastering the technology on a virtuoso level.

Usually technological solutions become obsolete within a couple of years when they are not part of a supported industry standard. Thus lack of potential virtuosity becomes an issue again. How can a traditional musical instrument be mastered without practicing it every day? And how can the theremin of Pamelia Kurstin or the Lady's Glove of Laetitia Sonami be so?

This is a call for virtuosity in the world of non-traditional and digital music tools either by composers (in dealing with computer-aided-composition tools), performers (in mastering new expressive instrumental technology) or both at the same time. We talk about new shapes of virtuosity, which is technologically dependent on the one hand, but it always demands our time, patience and continuity on the other.

\section{( 4 )}

Academic knowledge has been counterbalanced by a widely accessible internet knowledge base, often produced by universities themselves. Young people don't necessarily need to enter university in order to learn about harmony, scoring, acoustics, physical computing or any other discipline. They even are able to follow great on-line lectures and access large portions of information that academic researchers make available.

The dichotomy of academic versus non-academic in music has been diminished to a large extent - thanks to technology, which seems to act like a tool of democratization.

Yet still it is above all the academic community which is able to contextualize things, introduce hierarchy into the flood of information (particularly toward rather younger people today, who tend to rely upon the first page of Google search). And also it initiates discourses connecting present time to the history of music knowledge.

As a radio producer I have been able to work with two different types of artists. The first group I'd call composers. They come to the sound studio with a traditional background of music education - they learned about harmony, form theory and acoustics and they usually can articulate their ideas using meaningful terms, so that we can discuss them as musicians. Often their artistic proposals reveal rather conservative approaches in terms of sound aesthetics and /or conceptual solutions.

The other group emerges from a wide variety of artists, who deal with sound thanks to accessible technology (either elementary or advanced). They are visual artists, poets, filmmakers, theatre performers, architects and amateur musicians who enter into creative discourse of music and technology. They all use the sound studio in order to shape sound in time, thus they become "composers". Only I'd rather call them sound creators within a given context. They are usually able to propose very compelling conceptual, 
technological or sound solutions but a considerable lack of a compositional approach toward the time domain in music can be often observed. Also, the dichotomy of knowledge versus feeling becomes an issue in the articulation of artistic ideas and expressing them within a time-based context.

As a radio producer I have always wished to work with artists who represent a mixture of those attitudes. Following the given presentation, this is a call for openness, which can result in useful enriching of both academic and non-academic communities, combining knowledge and experience with unbiased conceptual attitudes, which calms the academic / non-academic battle field.

On the other hand there is the notion of higher and lower culture, which is still part of our cultural identity. And again I am bringing back the democratizing character of technology, upon whose influence the traditional notion of high and low has becoming eroded, as well as the claim that everyone can be composer today.

I am not able to find a reasonable solution to this kind of dichotomy. But I feel music sociologists would probably be able to guide a meaningful archaeology of such a dichotomy over different periods in the past.

And among all, this is a call for intensifying interdisciplinary awareness, which helps us to stay tuned-in and open-minded.

\section{Private solution}

For some years I had been looking for a tool which would allow me to interact with digital music content. And I found a tool which allows for the transformation of the gestural world of our hands into metaphorical shapes of sounds and timbres. Thus in 2007 my research with the Wacom tablet as a performance tool for live sound performance began and it happened in CNMAT, UC Berkeley.

The Wacom Tablet research is primarily based in real-time methods ${ }^{6}$. It suggests strategies for how hand gestures / tablet pen movement can initiate immediate sonic computer responses. There are specific processes, which are of particular importance to me as composer and performer: synthesis and playback control, real-time spectral model operations and the spatial diffusion of sound.

The tablet is a two-dimensional field, which we access using a special pen.

In 2013 a new touch-based version of the tablet (Intuos pen \& touch small, CTH480) added independent functionality on top of what previous pen-only tablets offered. This represents heavy added value according to current commercial touch based control surfaces: a combination of touch-based gesture with tactile and precise pen movement.

The basic requirement while building the virtual software instrument controlled by the Wacom tablet has been an openness regarding sound / musical material. I wanted to have a virtual "skeleton / body of an instrument", which can be filled with different

6 WANDERLEY, Marcelo M. Gestural Controll Of Music. International Workshop - Human Supervision and Controll in Engineering and Music, Kassel, Germany, Sep 21-24, 2001. 
sonic material at any time while keeping the same frame of interaction. There are two levels of such tablet interaction:

- resonating autonomous material using different synthesis, re-synthesis and samplebased methods,

- interaction with live sound input.

The instrument is typically connected to from four to eight speakers, which are spread around the performance space. Sound diffusion in real time during performance is integral and is currently being further developed towards use in multi-speaker arrays.

The complexity of the presented virtual instrument requires not only well prepared audio content, or let's say "a virtual orchestration"7, it also calls for a large period of practice towards real instrumental virtuosity. It is the tactile sensitivity of our hands, which can be responsible for very different performance results with minor movement changes.

As such, the tablet interaction has become an integral part of my compositional and performance activities, not only in my acousmatic work, but also when preparing sound material for my chamber or orchestral works, as well as when developing sound design or soundtracks for radio or film productions. ${ }^{8}$

\section{Conclusion}

To conclude all this easily: discovering the physical / analog through the perspective of the virtual / digital, learning from outside academia and penetrating non-academic worlds, practicing in order to become virtuoso and last but not least (perhaps in a form of aphorism) - not being afraid of becoming obsolete in the world of technology in order to master great piece of art.

\section{Bibliography}

AGOSTINHO, Gilberto, BARTOŠ, Daniel, HEJL, Matouš, RATAJ, Jakub, TROJAN, Jan, RATAJ Michal. Dotknout se zvuku, in: Opus Musicum 47, Nr. 4 / 2015, pp. 58-80.

LANDY, Leigh: La musique des sons / The Music of Sounds. MINT - Série Musique et nouvelles technologies nr. 3-2007

7 WESSEL, David, WRIGHT, Matthew, SCHOTT, John: Intimate Musical Control of Computers with a Variety of Controllers and Gesture Mapping Metaphors, in: Proceedings of the 2002 Conference on New Instruments for Musical Expression (NIME-02), Dublin, Ireland, May 24-26, 2002.

8 For detailed description of tablet interaction (Czech only) see: AGOSTINHO, Gilberto, BARTOŠ, Daniel, HEJL, Matouš, RATAJ, Jakub, TROJAN, Jan, RATAJ Michal. Dotknout se zvuku, in: Opus Musicum 47, Nr. 4 / 2015, pp. 58-80. 
RATAJ, Michal: Electroacoustic Music and Selected Concepts of Radio Art. PFAU Verlag 2010. [cit. 2016-11-18]. URL: < http://www.pfau-verlag.de/pdf_art/27405.pdf>. Czech edition: RATAJ, Michal: Elektroakustická hudba a vybrané koncepty radioartu. AMU \& KANT, Praha 2007.

RATAJ, Michal: Discontinuity, paradigm change and new crafts of sound composition, in: Electronic Music Today. Where are we going and what are we doing. Martin Flašar - Daniel Matej - Michal Rataj (eds.). Janáčkova akademi múzických umění v Brně, 2014, p. 14-27.

TIMMERMANS, Hans, ed.: Is the sky the limit? In Proceedings of the 42st International Computer Music Conference, 12-16 September 2016. HKU University of the Arts Utrecht, HKU Music and Technology, 2016. pp. XXIII-XXVII.

WANDERLEY, Marcelo M. Gestural Controll Of Music. International Workshop - Human Supervision and Controll in Engineering and Music, Kassel, Germany, Sep 21-24, 2001.

WESSEL, David, WRIGHT, Matthew, SCHOTT, John: Intimate Musical Control of Computers with a Variety of Controllers and Gesture Mapping Metaphors, in: Proceedings of the 2002 Conference on New Instruments for Musical Expression (NIME-02), Dublin, Ireland, May 24-26, 2002.

ZBYSZYNSKI, Michael, WRIGHT, Matthew, MOMENI, Ali, CULLEN, Daniel: Ten Years of Tablet Musical Interfaces at CNMAT, in: Proceedings of the 2007 Conference on New Interfaces for Musical Expression (NIME07), New York, USA, p. 100-105. 